\title{
The Convective Instability Pathway to Warm Season Drought in Texas. Part I: The Role of Convective Inhibition and Its Modulation by Soil Moisture
}

\author{
BOKSOON MyOUnG* AND JOHN W. NIELSEN-GAMMON \\ Department of Atmospheric Sciences, Texas A\&M University, College Station, Texas
}

(Manuscript received 24 November 2008, in final form 16 March 2010)

\begin{abstract}
This research is designed to investigate how convective instability influences monthly mean precipitation in Texas in the summertime and to examine the modulation of convective instability and precipitation by local and regional forcings. Since drought results from the accumulated effects of deficient precipitation over time, this study is expected to shed light on the physical and dynamical mechanisms of the initiation and maintenance of serious droughts as well. The focus in Part I of this two-part study is on identification of the controlling convective parameters and, in turn, the surface-based processes that cause variations in these parameters. NCEP-NCAR reanalysis data and observed precipitation data, correlation analysis, multiple linear regression analysis, and back-trajectory analysis are used to reveal the underlying dynamics of their linkage and causality.

Monthly mean precipitation is modified mainly by convective inhibition (CIN) rather than by convective available potential energy (CAPE) or by precipitable water. Excessive CIN is caused by surface dryness and warming at $700 \mathrm{hPa}$, leading to precipitation deficits on a monthly time scale. While the dewpoint temperature and thermodynamics at the surface are greatly affected by the soil moisture, the temperature at $700 \mathrm{hPa}$ was found to be statistically independent of the surface dewpoint temperature since the $700-\mathrm{hPa}$ temperature represents free-atmospheric processes. (These free-atmospheric processes are the focus of the companion paper.) Finally, the strong correlations among precipitation, soil moisture, and CIN, as well as their underlying physical processes, suggest that the tight linkage between precipitation and soil moisture is not only due to the impacts of precipitation on soil moisture but also to the feedbacks of soil moisture on precipitation by controlling CIN
\end{abstract}

\section{Introduction}

Since Texas receives most of its annual average precipitation between April and September, and potential evapotranspiration is high during that time, a summertime precipitation deficit in Texas may bring serious agricultural impacts during the growing season. Due to the strong interaction between land and atmosphere through soil moisture in the south-central United States (Koster et al. 2004), reduced precipitation over an initial period may induce further precipitation deficits, making Texas particularly vulnerable to drought. In Texas, the

\footnotetext{
* Current affiliation: Center for Climate/Environment Change Prediction Research, Ewha Womans University, Seoul, South Korea.

Corresponding author address: John Nielsen-Gammon, Dept. of Atmospheric Sciences, Texas A\&M University, 3150 TAMU, College Station, TX 77843-3150.

E-mail: n-g@tamu.edu
}

state-wide warm season droughts of 1996 and 1998 produced widespread crop failure and $\$ 5$ billion and $\$ 6$ billion, respectively, were lost through agricultural damage in each event (NCDC 2006). The more wide-ranging drought in 1980 in the south-central and eastern United States was associated with $\$ 20$ billion in damages in agriculture and related industries.

However, the skill levels of the statistical and dynamical predictions of monthly and seasonal precipitation are only marginal (e.g., Saha et al. 2006) and thus need to be substantially improved. The forecast skill for summers is smaller than that for winters, which is partially due to the unclear linkage between tropical SST anomalies and subtropical and extratropical climate variabilities in summers. One of the difficulties in establishing the relationships between SST anomalies and summer precipitation variations in the south-central United States is the substantial influence of local processes and feedbacks associated with soil moisture (Atlas et al. 1993; Helfand and Schubert 1995). 
Many efforts have been made to determine the origins and development processes of droughts in the Great Plains (Trenberth et al. 1988; Trenberth and Branstator 1992; Lyon and Dole 1995; Trenberth and Cuillemot 1996; Sud et al. 2003). Most studies have focused on the 1988 drought in the Great Plains and found a significant remote influence from anomalous sea surface temperatures (SSTs) in the tropical and extratropical Pacific and a local influence from reduced soil moisture; the 1988 drought was initiated by the former through induction of upper-level anticyclonic circulations and maintained by the latter. This result was consistent with the inferred causes of droughts in the south-central United States in 1980 and 1998 (Namias 1982; Hong and Kalnay 2002).

Convective precipitation such as occurs mainly over tropical regions becomes the primary characteristic of summertime rainfall in Texas (Clark 1960; Mintz 1984), as the subtropical jet weakens and the polar jet migrates to the north near the Canadian boarder. On monthly and seasonal time scales, thermodynamic characteristics seem to be crucial to the variability of tropical deep convection (Firestone and Albrecht 1986; Kloesel and Albrecht 1989; Fu et al. 1999; Biasutti et al. 2004; Zveryaev and Allan 2005). Since the precipitation characteristics of Texas in summertime are similar to those in the tropics in that convective precipitation prevails, these findings suggest that thermodynamic characteristics and changes in convective instability would be important to the variation of summer precipitation in Texas. As Myoung and Nielsen-Gammon (2010a, hereafter MN10) discussed, an "ingredients based" approach focused on key convective parameters isolates the direct impacts of the environment upon convection. On a monthly time scale, the overall convection and precipitation may depend not just on the mean values of key convective parameters but also on their variability within a month, but it is still expected that the mean parameter values should have a substantial influence on the monthly mean convection.

Recently, MN10 examined the modulation of convective instability on precipitation throughout the globe at locations and during seasons where convective precipitation is dominant. Their simple correlation analysis between the convective parameters [convective inhibition (CIN), convective available potential energy (CAPE), and precipitable water (PW)] and National Centers for Environmental Prediction-National Center for Atmospheric Research (NCEP-NCAR) reanalysis precipitation revealed that the variability of monthly mean precipitation is significantly controlled by the convective parameters and the most important convective parameter varies by regions and seasons. CIN is strongly correlated with precipitation over the summer continents in the Northern Hemisphere and Australia, while PW and CAPE are strongly correlated with precipitation over tropical oceans.

The present study (Part I) and its companion study (Myoung and Nielsen-Gammon 2010b, hereafter Part II) investigate more closely the relationship between convective instability and precipitation in the warm season in Texas. The most important parameter(s) for precipitation variability will be determined using observed precipitation data and calculated values of CIN and CAPE rather than the reanalysis precipitation and proxies for CIN and CAPE, as in MN10. Although we will examine the variability of the monthly mean precipitation, our major motivation is to understand the thermodynamic atmospheric structure associated with precipitation deficits that may cause or enhance drought in Texas during the summertime and the main goal of this study is to elucidate the primary contributing factors to the most important convective parameter(s). As noted previously, since the life cycle and mechanistic characteristics of the summer droughts in Texas are similar to those over the Great Plains, it is expected that upper-level anticyclonic circulation and reduced soil moisture may play important roles in causing precipitation deficits as well. However, unlike previous research, this study will explore how these factors modulate the thermodynamic characteristics and thereby affect drought. The local surface-based processes and large-scale circulations responsible for the precipitation deficits and droughts will be identified by statistical methods such as linear correlation and regression analyses among the parameters representing physical and dynamical properties or processes. Part I investigates the thermodynamic structure and related surface variables and processes, while Part II will investigate the variables and processes in the free troposphere. It will be shown that local and large-scale processes influence precipitation and drought through different mechanisms.

Section 2 outlines the data and methods used in this study. Section 3 investigates the characteristics of summertime Texas precipitation and the modulation of precipitation by convective instability. Section 4 then examines the most important parameters affecting convective instability. The major results and conclusions of this study are summarized in section 5 .

\section{Data and methods}

The monthly precipitation data used in this study is U.S. climate division data obtained from the National Climatic Data Center (NCDC). While Texas is composed of 10 climate divisions, monthly precipitation is 
strongly correlated among the different regions of Texas, implying that mechanistic characteristics of precipitation are fairly uniform across Texas. Thus, an area-weighted, state-wide averaged precipitation was calculated and logtransformed for each month and used as a primary monthly mean precipitation (PRCP) dataset.

The data for analysis of the probability distribution function (PDF) of Texas precipitation are from the U.S.Mexico daily precipitation analysis gridded at $0.25^{\circ} \times$ $0.25^{\circ}$. This dataset is derived from NCDC daily Cooperative Observer Program (COOP) stations, other daily station data received by the Climate Prediction Center (CPC), and daily accumulations from the hourly precipitation dataset. Its monthly averaged precipitation in Texas is highly correlated with PRCP.

The third dataset comes from the NCEP-NCAR reanalysis (Kalnay et al. 1996) and is gridded at $2.5^{\circ} \times 2.5^{\circ}$. The NCEP Medium-Range Forecast spectral model and the operational NCEP Spectral Statistical Interpolation were used for the NCEP-NCAR assimilation. Datasets include diagnostic variables like evaporation, soil moisture, and sensible and latent heat fluxes that are generated by the model's physical parameterizations, as well as instantaneous variables like temperature, specific humidity, geopotential height, and winds. The former are less reliable than the latter because they are more influenced by the model parameterization. However, although the surface heat fluxes, evaporation, and soil moisture of the reanalysis on a daily time scale tend to be under- or overestimated compared to the observations (Brotzge 2004; Betts et al. 1996b) over the central and midwestern United States, their monthly or seasonal mean values are in good agreement with the observations and other reanalyses (Betts et al. 1996b; Roads and Betts 2000; Brotzge 2004; Dirmeyer et al. 2004).

Monthly mean values computed from daily reanalysis values and then averaged at the 11 grid points within Texas are utilized in this study. The time domain for this study includes the summer months from 1948 to 2003, with an emphasis on July when disorganized convective precipitation is most prevalent.

Among the various fields of the NCEP-NCAR reanalysis data, Table 1 lists variables that may play an important role in modulating convective instability and associated precipitation. The variables include surface and tropospheric variables. The tropospheric variable called moisture flux divergence (MFD) is the vertically integrated horizontal divergence of moisture flux, as computed directly from winds and specific humidity on the respective model pressure levels. MFD $[\nabla \cdot(q \mathbf{V})]$ consists of an advection term, $\operatorname{ADV}(\mathbf{V} \cdot \nabla q)$, and a divergence term, DIV $(q \boldsymbol{\nabla} \cdot \mathbf{V})$, where $q$ is the specific humidity and $\mathbf{V}$ is the horizontal wind.
TABLE 1 . Frequently used acronyms and symbols.

\begin{tabular}{|c|c|c|}
\hline Category & $\begin{array}{c}\text { Acronym or } \\
\text { symbol }\end{array}$ & Meaning \\
\hline Surface & SM & Soil moisture \\
\hline Surface & $\mathrm{SH}$ & Sensible heat flux \\
\hline Surface & LH & Latent heat flux \\
\hline Surface & $\mathrm{Td}$ & Surface dewpoint \\
\hline Surface & Ts & Surface temperature \\
\hline Surface & DP & Dewpoint depression \\
\hline Surface & $\theta \mathrm{e}$ & $\begin{array}{l}\text { Surface equivalent } \\
\text { potential temperature }\end{array}$ \\
\hline Tropospheric & ADV & $\begin{array}{l}\text { Advection term of the } \\
\text { moisture flux divergence }\end{array}$ \\
\hline Tropospheric & DIV & $\begin{array}{l}\text { Divergence term of } \\
\text { the moisture flux divergence }\end{array}$ \\
\hline Tropospheric & MFD & Moisture flux divergence \\
\hline Tropospheric & OMG & $\begin{array}{l}\text { 500-850-hPa mean } \\
\text { vertical motion }\end{array}$ \\
\hline Tropospheric & Tlt & Temperature at $700 \mathrm{hPa}$ \\
\hline
\end{tabular}

To explore relationships between the convective instability parameters and precipitation, CIN and CAPE are computed using monthly mean vertical profiles of temperature and dewpoint averaged across Texas. This differs from the instantaneous values of thermodynamic parameters, which are used in the reanalysis model's convective scheme (Grell 1993). The General Meteorological Package (GEMPAK) is used to compute the CIN, CAPE, lifted condensation level (LCL), and level of free convection (LFC). For PW, monthly mean precipitable water from the reanalysis is averaged over Texas.

In the present study, linear correlation analysis is performed among precipitation, convective instability parameters, surface variables, and tropospheric variables to reveal the relationships among the variables. In addition, we use linear regression analysis to determine the parameters or variables most relevant to precipitation. The resulting Pearson correlation coefficients $(r$, hereafter) indicate the strength of a linear relationship between the two fields. Assuming independent, normally distributed data, \pm 0.34 is roughly the $99 \%$ confidence level for a nonzero correlation for the July samples with $N-2=$ 54 degrees of freedom. The existence of this level of statistical significance will be indicated by a star in the figures that follow.

We will compare the magnitudes of correlation coefficients to determine, for example, which variables are more or less correlated, or which pathways are more important in controlling a variable. To test the null hypothesis that two dependent correlations, $r_{j k}$ and $r_{j h}$, are equal, we use Williams' (1959) $T$ statistic (Steiger 1980): 


$$
T=\left(r_{j k}-r_{j h}\right) \sqrt{\frac{(N-3)\left(1+r_{k h}\right)}{2\left(1-r_{j k}^{2}-r_{j h}^{2}-r_{k h}^{2}+2 r_{j k} r_{j h} r_{k h}\right)+\frac{1}{4}\left(r_{j k}+r_{j h}\right)^{2}\left(1-r_{k h}\right)^{3}}},
$$

which has a $t$ distribution with $(N-3)$ degrees of freedom. In this case, $N=56$. We compute the first-order partial correlation between $j$ and $k$ while controlling for $h\left(r_{j k . h}\right)$ as (Chen and Popovich 2002)

$$
r_{j k . h}=\frac{r_{j k}-r_{j h} r_{k h}}{\sqrt{1-r_{j h}^{2}} \sqrt{1-r_{k h}^{2}}}
$$

and test for significance as recommended by Chen and Popovich (2002).

Although correlation analysis does not identify causality between the two variables, understanding the physical mechanisms between the two often allows us to determine their possible causality. For example, a significant positive correlation was found between temperature and vertical motion at a given pressure level and location: warmth is linked with descending motion. Because relatively warm air tends to ascend due to buoyancy, downward motion cannot be caused by the buoyancy of the warm air. Instead, because downward motion causes adiabatic warming, subsidence must be driving the positive correlation. Physical reasoning combined with correlation analysis makes it possible to infer causality between many of the correlated variables. This technique is used in this study to find pathways causing a deficit of convective precipitation. Great caution is needed in inferring causation because some group of "third variables" can be causing variance in both variables as well.

\section{Precipitation and convective instability parameters}

First, we investigate whether the monthly precipitation is strongly controlled by the local convective instability parameters that are known to govern convective precipitation frequency and intensity on shorter time scales. Monthly anomalies (departures from the 56-yr monthly mean) of PRCP and convective instability parameters in July and August are plotted in Fig. 1 while those only in July are exhibited in Fig. 2. Note that two samples in August were omitted in Fig. 1 because these months included days with no instability, making CAPE and CIN undefined. Correlations are less tight in July and August (Fig. 1) than in July only (Fig. 2). However, in both cases PRCP is most strongly correlated with CIN, moderately with PW, and least with CAPE. The correlation of PRCP is statistically significant at the $99 \%$ level only with CIN and PW.
The negative relationship between CIN and precipitation is due to the influence of CIN on precipitation. Since CIN is a measure of the amount of energy needed to initiate convection, precipitation is suppressed when CIN is relatively high, even if substantial CAPE exists. Given particular initial values of CAPE, PW, and CIN, on the other hand, convective activity and rainfall do not necessarily decrease CIN (MN10). This allows PRCP to be significantly correlated with $\mathrm{CIN}(r=-0.68, p<$ 0.0001 in July and August and $r=-0.75, p<0.0001$ in July) and more loosely correlated with CAPE $(r=0.02$, $p=0.8$ in July and August and $r=0.33, p=0.015$ in July). The smaller correlation between CAPE and PRCP $(T=6.0, p<0.0001$ in July and August and $T=$ $5.4, p<0.0001$ in July) is partially because the monthly averaging process may reduce the relationship between CAPE and subsequent precipitation as convective activity can destroy large CAPE (DeMott and Randall 2004).

For PW, on one hand, substantial moisture is a prerequisite for rainfall, causing a positive relationship. On the other hand, precipitation reduces the liquid-phased moisture that is transformed from water vapor in the troposphere, which directly results in a decrease in PW. However, the latter effect becomes less important than the former effect once the positive feedback of the subsequent wet soil enhances the PW through increased surface evaporation. Consequently, precipitation on a monthly time scale tends to be positively correlated with PW $(r=0.34, p=0.0003$ in July and August and $r=0.43$, $p=0.001$ in July), but not as large as with $\mathrm{CIN}(T=2.6$, $p=0.011$ in July and August and $T=4.2, p<0.0001$ in July).

The results in Figs. 1 and 2 suggest that thermodynamic characteristics and changes in convective instability are as relevant to the interannual variability of summer precipitation in Texas as in the tropics. The monthly mean precipitation in summertime in Texas is modulated primarily by the amount of CIN rather than by that of CAPE or PW, which is consistent with MN10.

A moderate correlation is found between CIN and CAPE $(r=-0.59, p<0.0001$ in July and August and $r=$ $-0.62, p<0.0001$ in July; scatterplots not shown). The correlation between CIN and CAPE may be because both are greatly influenced by the initial conditions of a parcel. Nevertheless, precipitation is tightly correlated with CIN and poorly with CAPE (Fig. 2). This implies that there is another factor (or perhaps several factors) 

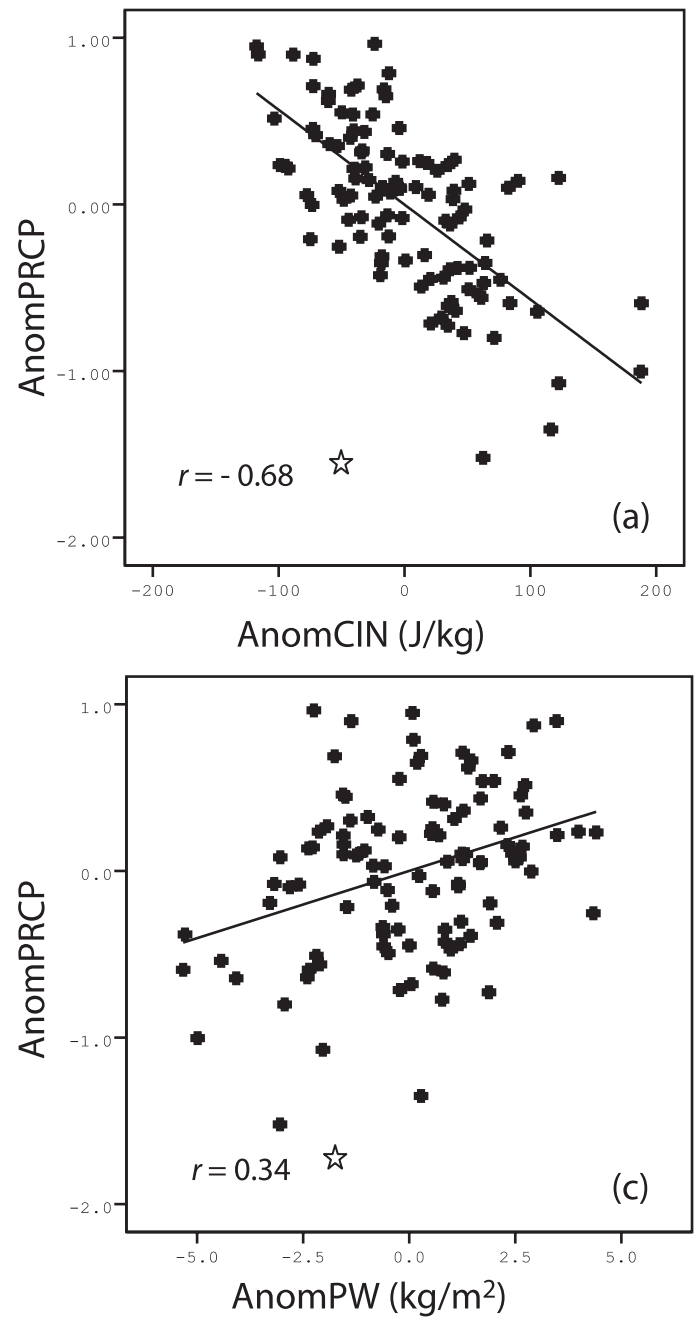

besides surface conditions controlling CIN but not CAPE, and thereby exerting a strong influence on monthly precipitation. This will be discussed in Part II.

Meanwhile, the correlation between PRCP and CIN in July $(-0.75)$ is stronger than in August $(-0.61)$. Assuming independent samples, the $z$ score (Fisher 1921) indicates that the difference is not statistically significant $(z=1.31, p=0.19)$. As mentioned previously, mean convective parameters could not be computed in 2 months out of the 56 months in August. Thus, for better quality of results, further analyses will focus on the month of July.

Variations in monthly mean precipitation can be caused by modification in the frequency of rainfall events, or in the intensity of rainfall per event, or by a combination of both on a daily time scale. The fact that CIN, the most relevant convective instability parameter to July precipitation, tends to be associated with the initiation of convection (Mapes 2000) suggests that dry summer months in Texas are due primarily to the reduced number



FIG. 1. Scatterplot between PRCP and (a) CIN, (b) CAPE, and (c) PW. They are monthly anomalies in July and August. of rain days, or the reduced frequency of deep convection, rather than reduced precipitation intensity. To test this hypothesis, the probability distribution function (PDF) of daily July precipitation in Texas was investigated with respect to the number of rain days and the average precipitation intensity. A rain day is defined as a day whose daily precipitation is greater than or equal to $1 \mathrm{~mm}$. For each July, the number of rain days and precipitation intensity (e.g., averaged rain amount per rain day) was calculated at each grid point in the daily U.S.Mexico precipitation data. The monthly values were then averaged over all the grid points in Texas to obtain July mean series for the number of rain days (RDs) and the precipitation intensity $(\mathrm{PI})$.

Figures $3 \mathrm{a}$ and $3 \mathrm{~b}$ are scatterplots of precipitation with RDx and PI. Both RDx $(r=0.94, p<0.0001)$ and PI $(r=$ $0.81, p<0.0001)$ are significantly correlated with total precipitation, and RDx and PI are also positively correlated ( $r=0.70, p<0.0001$, scatterplot not shown). This 

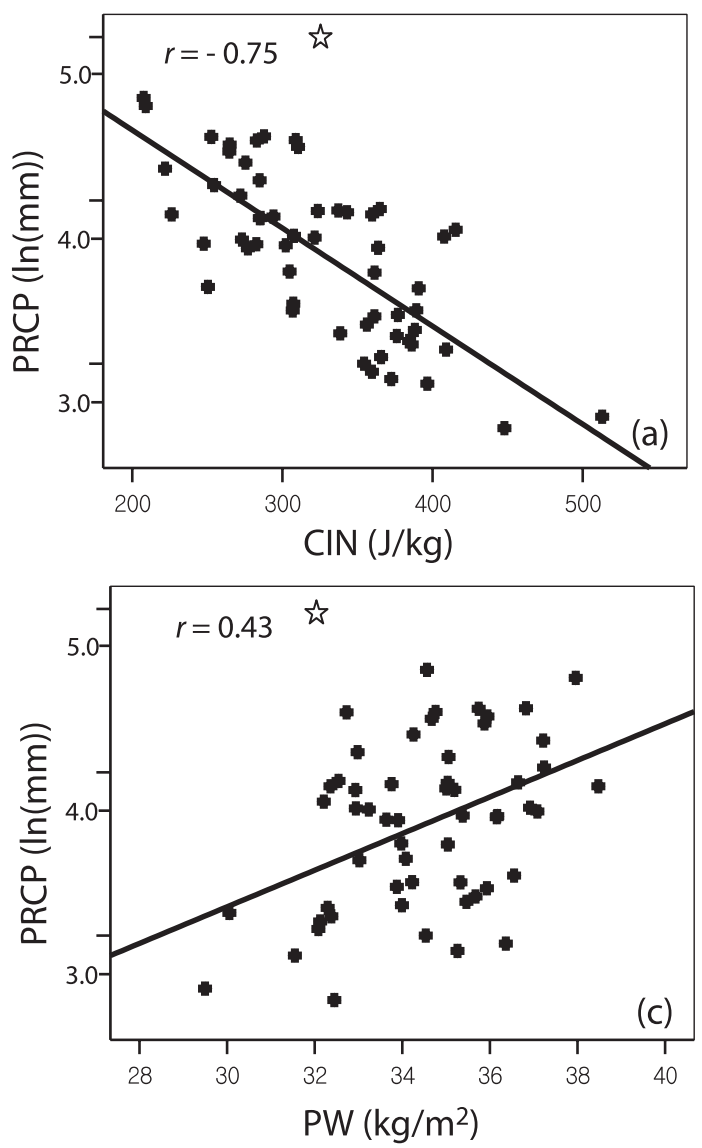

feature implies that while less precipitation is correlated with fewer rain days and reduced intensity, the total precipitation is more strongly influenced by the former in Texas in summertime ( $T=3.8, p=0.0004)$. While an increase of CIN is associated with a decrease both in rain days and intensity, stronger correlation $(T=3.6, p=$ 0.0007) of CIN with RDx $(r=-0.79, p<0.0001)$ (Fig. 3c) than with PI $(r=-0.55, p<0.0001)$ (Fig. 3d) suggests that larger CIN tends to reduce the number of rain days.

Combining the results of Fig. 3, Fig. 4a illustrates the correlation coefficients of CIN with RDx, PI, and PRCP. Similar illustrations are shown for CAPE and PW as well in Figs. 4b and 4c, respectively. The strong correlation of CIN with RDs $(-0.79)$, combined with the strong correlation of RDs with PRCP, results in the high negative correlation of CIN with PRCP $(-0.75)$. The first-order partial correlation of CIN with PRCP while controlling for RDs is near zero $(r=-0.03, p=0.80)$, and the first-order partial correlation of CIN with PI while controlling for RDs is also small $(r=0.01, p=$ 0.95), implying that CIN's entire relationship with PRCP is through RDs. For CAPE, although it is more tightly connected to PI than to RDs, the magnitude of the correlation to PI is substantially smaller than that of CIN with

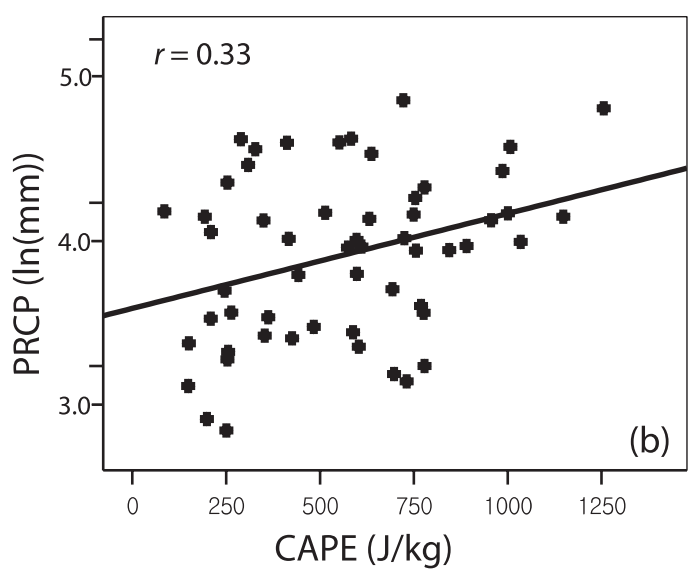

FIG. 2. Scatterplot between PRCP and (a) CIN, (b) CAPE, and (c) PW only in July.

PI $(T=-2.1, p=0.04$; see Fig. 4b). PW does not seem to affect RDx, PI, and PRCP as much as CIN does, either (for RD, $T=-5.7, p<0.0001$; see Fig. 4c). When one recalls that $\mathrm{CIN}$ is the energy needed to initiate convection, it seems plausible to conclude that CIN controls the number of rain days and the number of rain days affects the monthly precipitation.

\section{Processes controlling convective inhibition}

\section{a. Parameterization of CIN}

Fundamentally, CIN is determined by the surface temperature and dewpoint and the vertical temperature distribution, ignoring the minor contribution to the CIN variability of virtual temperature effects. Since the vertical temperature distribution is continuous on a monthly time scale, a reduction in the number of degrees of freedom is necessary to facilitate further analysis. A successful parameterization of CIN in terms of two or three simple variables will allow us to investigate the modulation of $\mathrm{CIN}$ and precipitation by local land surface processes and large-scale circulations through their effects on those two or three variables. 

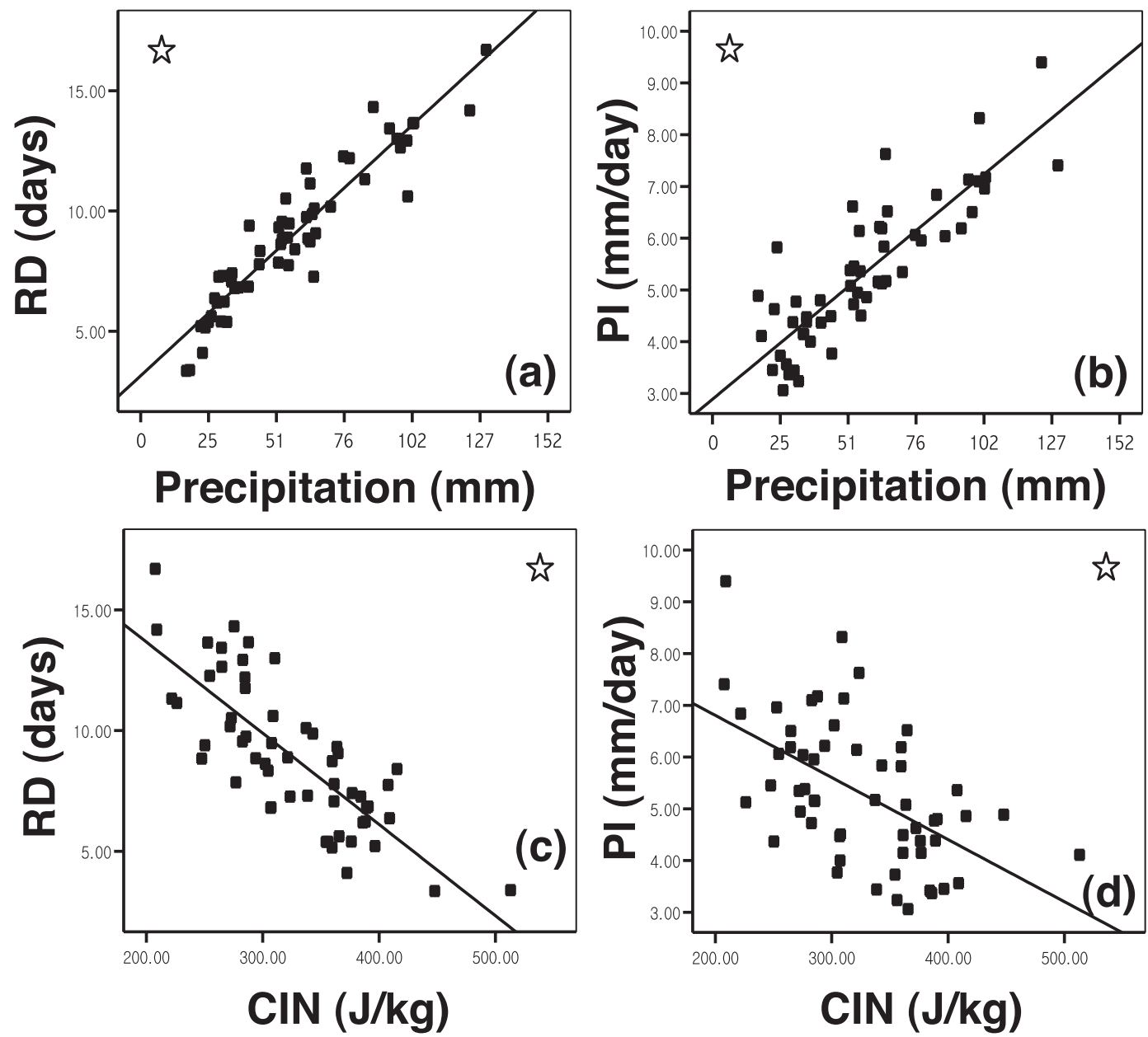

FIG. 3. Scatterplots of the number of RDs and PI with (a),(b) precipitation without the natural log transform and (c),(d) CIN.

Here, we hypothesize that CIN is controlled by local surface-based variables that represent surface-based processes. To test this hypothesis, linear regression analysis on CIN with various combinations of independent variables using surface temperature (Ts), surface dewpoint (Td), and temperature at $700 \mathrm{hPa}$ (Tlt) is employed. While Ts and Td are the surface variables that greatly modify the magnitude of CIN by definition, Tlt is a suitable proxy for the free-tropospheric temperature just below the LFC (MN10). The results of the regression analysis are shown in Table 2. Among the univariate and bivariate predictors, $(\mathrm{Tlt}-\mathrm{Td})$ produces the closest fit to CIN while (Ts $-\mathrm{Td}$ ) and the bivariate regressions including ( $\mathrm{Ts}-\mathrm{Td}$ ) provide reasonably good approximations of CIN. However, the moist static energy approximated by $(\mathrm{Ts}+\mathrm{Td})$ estimates CIN poorly. The variable $(\mathrm{Tlt}-\mathrm{Td})$ represents the joint effects of warming (cooling) at $700 \mathrm{hPa}$ and surface dryness (wetness). The superior performance of the model employing $(\mathrm{Tlt}-\mathrm{Td})$ over $(\mathrm{Ts}-\mathrm{Td})$ as an independent variable indicates that CIN is controlled not only by surface-based variables (or processes) but also by low-tropospheric temperature (or processes).

Table 3 shows the correlations among CIN, Td, Ts, Tlt, and the surface sensible heat flux (SH). Tlt is correlated with CIN less tightly than are Ts $(T=-4.8, p<$ $0.0001)$ and $\mathrm{Td}(T=-1.85, p=0.07)$. Nevertheless, the superior performance of the model employing $(\mathrm{Tlt}-\mathrm{Td})$ over $(\mathrm{Ts}-\mathrm{Td})$ as an independent variable emphasizes the independent importance of Tlt in determining CIN. The result that low-tropospheric temperatures, as well as surface conditions, have a significant impact on monthly convective instability and precipitation is consistent with the model-based findings of Beljaars et al. (1996) for July 1993.

The answer to why Ts plays a secondary role in controlling CIN compared to Tlt even though it is more tightly correlated with CIN is found in the physical 

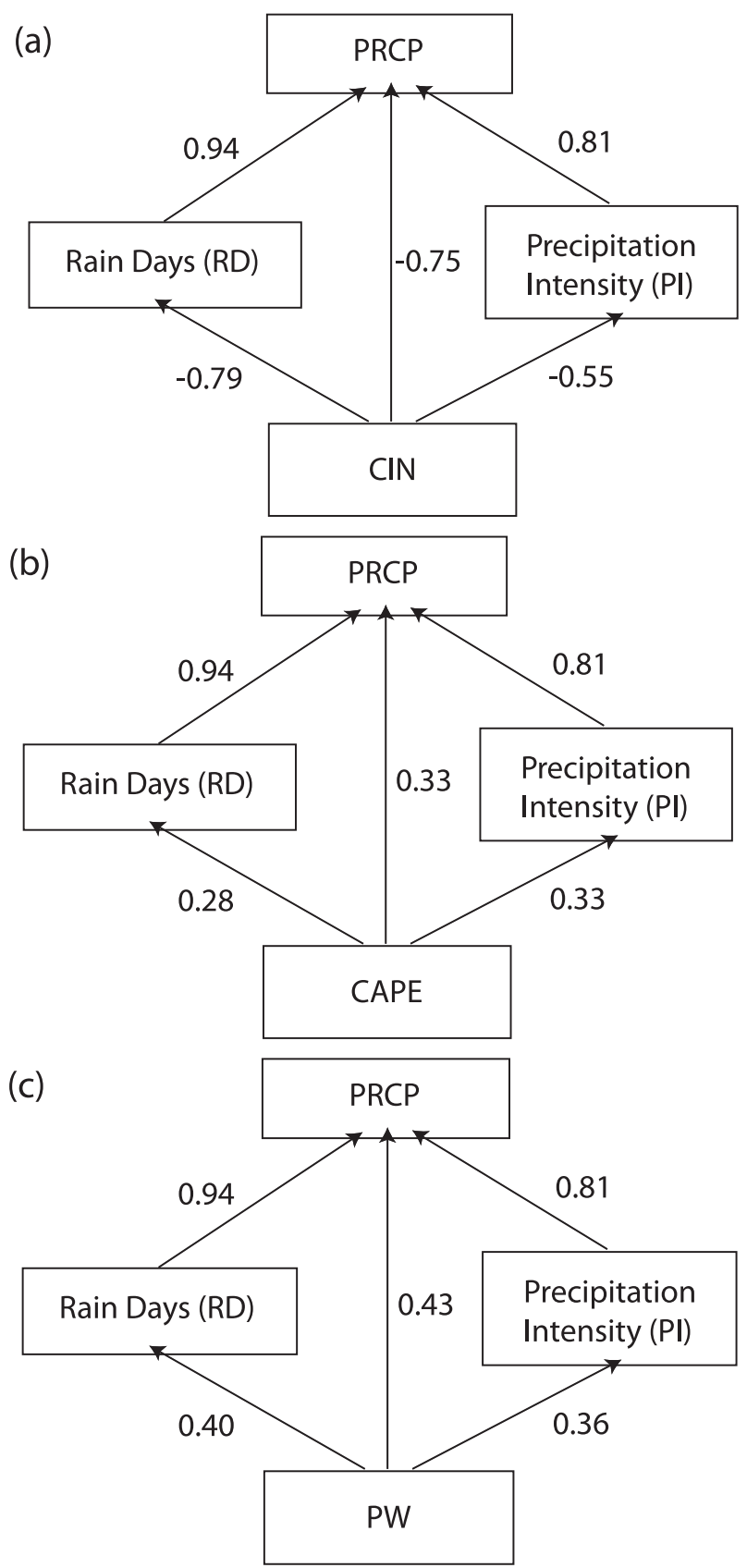

FIG. 4. Schematic illustrating the correlation coefficients of (a) CIN, (b) CAPE, and (c) PW with RD, PI, and PRCP.

relationship between Ts and Tlt. The strong positive correlation between Ts and Tlt $(r=0.71, p<0.0001)$ indicates a hotter $700-\mathrm{hPa}$ level as the surface warms. Simultaneous warming at the surface and at $700 \mathrm{hPa}$ can be caused by 1) excessive heating of surface air so that the top of the PBL reaches up to $700 \mathrm{hPa}$ or 2) entrainment of extremely warm low-tropospheric air, or air with similar thermodynamic characteristics to that at $700 \mathrm{hPa}$, into the ordinary PBL. Only possibility 2 is consistent with the expectation that Tlt represents freeatmospheric processes. If possibility 1 is true, then $\mathrm{SH}$, which helps determine PBL depth, would be linked with temperature at $700 \mathrm{hPa}$ but it would not affect temperature above the top of the PBL in case 2. Yet Tlt and Ts would be interrelated in both cases. Therefore, the key is whether SH is linked with temperature above the top of the PBL, represented by Tlt in this study.

The reanalysis dataset reveals that Tlt is weakly associated with $\mathrm{SH}(r=0.20, p=0.14)$ while the correlations between Tlt and Ts $(r=0.71, p<0.0001)$ and between Ts and SH $(r=0.69, p<0.0001)$ are relatively strong, respectively (Table 3 ). This supports not only the assumption that Tlt represents free-atmospheric processes but also the hypothesis that the correlation of Tlt with Ts is primarily due to the entrainment of 700-hPa air, or air with thermodynamic characteristics similar to those at $700 \mathrm{hPa}$, into the ordinary PBL. The result of linear regression analysis of Tlt and $\mathrm{SH}$ predicting Ts (Table 4) also shows that Tlt and SH, being mutually independent, produce a much closer fit to Ts than either of Tlt and SH alone does, so that both contribute to Ts in a physical sense.

Going back to the original question, why Tlt rather than Ts plays a critical role in determining CIN, we found that the surface temperature, Ts, is affected by both the temperature at $700 \mathrm{hPa}$ (Tlt) through entrainment and SH. SH is tightly linked with the surface latent heat flux (LH) and Td through soil moisture, which will be described below. Since Tlt is largely independent of $\mathrm{SH}$ and $\mathrm{Td}$, the variability of CIN is explained mostly by $\mathrm{Td}$ and the rest is explained by Tlt rather than by Ts.

\section{b. Local atmospheric variables controlling the key parameters of CIN}

Previously, it was shown that low-tropospheric warming as well as low surface specific humidity combine to result in large values of CIN. This can reduce convection and precipitation, leading to a deficit of summertime rainfall in Texas. The regression model for PRCP indicates that about $54 \%$ of the interannual variation in precipitation is explained by (Tlt - Td). In this section, we will investigate which local variables are tightly linked with $\mathrm{Td}$ and what processes control them in terms of modulating the convective instability, mainly through CIN. Factors and pathways controlling Tlt that represents free-tropospheric processes will be examined in Part II.

Table 5 shows the relationships between $\mathrm{Td}$ and several surface variables (SM, SH, LH, and Ts) and tropospheric variables (ADV, DIV, MFD, and OMG). While Td has a moderate (OMG) and weak (DIV, ADV, and MDF) relationship with tropospheric variables, it is strongly correlated with the surface variables. The correlation of $\mathrm{Td}$ 
TABLE 2. Results of linear regression analysis on CIN showing the adjusted coefficient of determination $\left(R_{a}^{2}\right)$, coefficients of each independent variable $\left(\beta_{0}, \beta_{1}\right.$, and $\left.\beta_{2}\right)$, multicollinearity (VIF), and $p$ value. In the $p$ value, boldface entries are statistically significant at the $99 \%$ level.

\begin{tabular}{|c|c|c|c|c|c|c|}
\hline Independent & $R_{a}^{2}$ & $\beta_{0}$ & $\beta_{1}$ & $\beta_{2}$ & VIF & $p$ value \\
\hline Ts & 0.630 & -982.4 & 46.7 & N/A & N/A & $<\mathbf{0 . 0 0 0 1}$ \\
\hline $\mathrm{Td}$ & 0.580 & 1156.7 & -44.2 & N/A & N/A & $<\mathbf{0 . 0 0 0 1}$ \\
\hline Tlt & 0.238 & -58.7 & 37.7 & N/A & N/A & 0.0001 \\
\hline$(\mathrm{Ts}-\mathrm{Td})$ & 0.847 & 33.6 & 31.5 & N/A & N/A & $<0.0001$ \\
\hline$(\mathrm{Ts}+\mathrm{Td})$ & -0.180 & 281.3 & 0.9 & N/A & N/A & 0.9051 \\
\hline$(\mathrm{Tlt}-\mathrm{Td})$ & 0.951 & 774.2 & 48.5 & N/A & N/A & $<\mathbf{0 . 0 0 0 1}$ \\
\hline Ts, Td & 0.845 & -50.2 & 33.4 & -29.8 & 1.23 & $<0.0001 /<0.0001$ \\
\hline Td, Tlt & 0.951 & 771.2 & -49.2 & 47.1 & 1.02 & $<\mathbf{0 . 0 0 0 1} /<\mathbf{0 . 0 0 0 1}$ \\
\hline$(\mathrm{Ts}-\mathrm{Td}), \mathrm{Td}$ & 0.845 & -50.2 & 33.4 & 3.5 & 3.61 & $<\mathbf{0 . 0 0 0 1} / 0.5468$ \\
\hline$(\mathrm{Ts}-\mathrm{Td}), \mathrm{Tlt}$ & 0.884 & -108.2 & 29.3 & 16.1 & 1.21 & $<0.0001 / 0.0001$ \\
\hline$(\mathrm{Tlt}-\mathrm{Td}), \mathrm{Ts}$ & 0.951 & 840.3 & 50.5 & -2.8 & 3.24 & $<\mathbf{0 . 0 0 0 1} / 0.3691$ \\
\hline
\end{tabular}

with the surface variables is caused primarily by modulation of SM (Betts et al. 1996a).

There are three processes by which SM can affect Td through changing the surface heat fluxes (Eltahir 1998). With an ample supply of soil moisture and an associated low Bowen ratio, surface evaporation $\mathrm{LH}$ is enhanced, which accompanies an increase of $\mathrm{Td}$ (direct effect through water budget balance). As SH decreases, reduced mixing of surface air with dry low-tropospheric air in the PBL keeps Td from dropping substantially (indirect effect through energy budget balance). Soil moisture also maintains the greenness of plants, thereby decreasing the albedo and increasing the fraction of absorbed solar radiation (indirect effect through radiation balance). All three effects result in an increase in Td when rainfall enhances SM, which is consistent with the high correlation coefficients between $\mathrm{Td}$ and $\mathrm{SH}$ and between Td and LH given in Table 5. While observations of soil moisture are limited spatially and temporally, $\mathrm{Pal}$ and Eltahir (2001) found critical impacts by soil moisture on the energy and water budgets using a regional climate model.

In Table 6, the correlations between Ts with SM are not as tight as those between $\mathrm{Td}$ and $\mathrm{SM}(T=-1.31, p=$ 0.20 ), which implies the likely existence of other important factors controlling the monthly mean surface temperature, such as cloud effects and feedback (Stephens and Webster 1981; Woodhouse and Overpeck 1998; Bony et al. 2006), in addition to soil moisture. One of these factors is the entrainment of free-atmospheric air into the PBL, as discussed in the previous section: $80 \%$ of the variation in Ts is explained by Tlt and SH. Here, $\theta \mathrm{e}$ is least correlated with soil moisture, presumably due to the opposing influences of Ts and Td associated with $\mathrm{SM}$ on $\theta \mathrm{e}$, so that it is poorly correlated with $\mathrm{PRCP}(r=$ $0.21, p=0.14)$. Similar results were found by Findell and Eltahir (1999), who examined physical pathways linking soil moisture to subsequent rainfall in Illinois during the summer. Our result using reanalysis data in Texas are consistent with theirs using observational data from Illinois. (Hereafter, "surface variables" will refer to $\mathrm{SH}$, LH, Td, Ts, and DP, excluding $\theta$ e.)

Since OMG does not influence Td directly, correlations in Tables 5 and 6 suggest that surface processes associated with soil moisture are the primary modulators of Td. Tight relationships among the surface variables likely originate from the strong interactions between the surface and the PBL through feedbacks between soil moisture and precipitation (Betts et al. 1996a; Koster et al. 2004). The large direct correlation between PRCP and SM $(r=0.63, p<0.0001)$ suggests nothing about the causality between the two, but precipitation has an obvious direct physical influence on soil moisture. In Table 6 , the relation among the surface variables with PRCP resembles that with SM, but with smaller correlation coefficients (the smallness being significant at the $99 \%$ level), except that the correlation coefficient of Ts with PRCP is as large as that with SM. These features indicate an important influence of rainfall on the surface variables through controlling SM on a monthly time scale.

While we have discussed so far how rainfall influences the surface variables through changing soil moisture content on a monthly time scale, are these correlations between precipitation and the surface variables entirely

TABLE 3. Correlations among CIN and surface variables for July mean values. Values in boldface are significant at the $99 \%$ confidence level.

\begin{tabular}{lrrrrr}
\hline \hline & CIN & Td & Ts & Tlt & SH \\
\hline Td & $-\mathbf{0 . 7 7}$ & & & & \\
Ts & $\mathbf{0 . 8 0}$ & $-\mathbf{0 . 4 3}$ & & & \\
Tlt & $\mathbf{0 . 4 9}$ & 0.14 & $\mathbf{0 . 7 1}$ & & \\
SH & $\mathbf{0 . 8 0}$ & $-\mathbf{0 . 8 5}$ & $\mathbf{0 . 6 9}$ & 0.20 & \\
\hline
\end{tabular}


TABLE 4. Adjusted coefficient of determination $\left(R_{a}^{2}\right)$ of regression models on Ts employing Tlt and SH as independent variable(s).

\begin{tabular}{cc}
\hline \hline Independent variable & $R_{a}^{2}$ \\
\hline Tlt & 0.489 \\
SH & 0.463 \\
Tlt, SH & 0.801 \\
\hline
\end{tabular}

due to the responses of soil moisture to rainfall? Although Koster et al. (2004) pointed out that the impacts of SM on precipitation are much weaker than the other direction of causality, the existence of an impact of soil moisture on precipitation is suggested implicitly in the correlation coefficients between PRCP, SM, and CIN represented in Fig. 5. First, it is assumed that SM affects CIN, causing the correlation coefficient of -0.85 ( $p<$ .0001 ), which is supported by the fact that Td is the most critical parameter for CIN. Then, if PRCP were to influence CIN through SM and the surface variables without a feedback, the magnitude of the correlation coefficient of PRCP with CIN $(r=-0.75, p<.0001)$ would be less than that with SM $(r=0.63, p<.0001)$, but it is instead substantially larger $(T=2.3, p=0.025)$. Indeed, the firstorder partial correlation between PRCP and SM while controlling for CIN is very small $(r=0.01, p=0.94)$, consistent with PRCP affecting SM over a period of several months while SM affects PRCP through CIN on an intramonth time scale. In summary, there seems to be a direct connection between PRCP and CIN. CIN, in turn, is greatly influenced by the surface thermodynamic characteristics that are controlled by soil moisture and antecedent precipitation.

Many studies, mostly model based, have investigated the positive feedback of soil moisture on subsequent rainfall (Rowntree and Bolton 1983; Mintz 1984; Oglesby 1991; Findell and Eltahir 1999; Pal and Eltahir 2001; Koster et al. 2004; Guo et al. 2006; Zhang et al. 2008). Since moisture availability is sensitive to not only surface evaporation but also moisture flux divergence, the response of precipitation to soil wetness varies by location and season. Sud and Fennessy (1984) and Sud and Smith (1985) found that over semiarid regions in their GCM model, notably India, an increased convergence of moisture produced by enhanced sensible heating in the planetary boundary layer was sufficient to compensate for the moisture deficit caused by the reduced evaporation resulting from dry soil. However, important feedbacks of soil moisture on maintaining warm season droughts in the central United States have been extensively documented in a number of studies (Namias 1982; Lyon and Dole 1995; Trenberth and Cuillemot 1996; Hong and Kalnay 2002; Sud et al. 2003; Schubert et al. 2004). In particular, Lyon and Dole (1995) found that decreasing trends in both precipitation and evaporation occurred despite the fact that an anomalous positive moisture flux convergence occurred over the drought region in the later months of the 1988 drought. Likewise, we find that the surface dewpoint is correlated much more strongly with soil moisture than with moisture flux divergence, indicating that a reduction in soil moisture plays a critical role in maintaining warm season droughts in Texas.

Because moisture flux convergence is a secondary influence on monthly summertime precipitation in Texas, no attempt has been made here to separately consider individual processes contributing to moisture flux convergence. Others have found that the nocturnal low-level jet (LLJ) and associated moisture flux convergence, as represented by the reanalysis data, tend to enhance deep convection and precipitation in the Great Plains during warm seasons (Higgins et al. 1997). The lack of importance of the moisture flux convergence in Texas may be due to the fact that Texas is south of the climatological nocturnal LLJ maximum, so an enhanced LLJ is associated with the competing effects of low-level divergence and enhanced moisture transport.

CIN has not previously been identified as the primary pathway by which soil moisture influences precipitation in Texas or in any other region. Most studies of the possible dependences of precipitation on soil moisture are model based, and different models are inconsistent in their representations of important parameterized processes by which soil moisture affects convection (Dirmeyer et al. 2006; Mo et al. 2006). Rarely have such studies considered convective inhibition explicitly. Hong and Pan (2000) noted that increased soil moisture simultaneously increased CAPE and decreased CIN over the central United States in summer, but did not attempt to assess the relative importance of the two effects. Similarly, Schär et al. (1999) found an increase in the level of free

TABLE 5. Correlations between surface dewpoint temperature and various surface and tropospheric variables.

\begin{tabular}{|c|c|c|c|c|c|c|c|c|}
\hline & \multicolumn{4}{|c|}{ Surface variables } & \multicolumn{4}{|c|}{ Tropospheric variables } \\
\hline & SM & $\mathrm{SH}$ & LH & Ts & $\mathrm{ADV}$ & DIV & MFD & OMG \\
\hline$r$ & 0.82 & -0.85 & 0.85 & -0.44 & 0.24 & -0.35 & -0.20 & -0.47 \\
\hline$p$ value & $<0.0001$ & $<0.0001$ & $<0.0001$ & 0.0009 & 0.08 & 0.01 & 0.16 & 0.0004 \\
\hline
\end{tabular}


TABLE 6. Correlations between surface variables and July mean precipitation and soil moisture. All boldface values are significant at the $99 \%$ level.

\begin{tabular}{lcccccc}
\hline \hline & Td & SH & LH & Ts & DP & $\theta \mathrm{e}$ \\
\hline SM & $\mathbf{0 . 8 2}$ & $\mathbf{- 0 . 9 4}$ & $\mathbf{0 . 9 1}$ & $-\mathbf{0 . 7 2}$ & $-\mathbf{0 . 9 1}$ & $\mathbf{0 . 5 8}$ \\
PRCP & $\mathbf{0 . 4 9}$ & $\mathbf{- 0 . 5 6}$ & $\mathbf{0 . 4 7}$ & $-\mathbf{0 . 7 5}$ & $-\mathbf{0 . 7 3}$ & 0.21 \\
\hline
\end{tabular}

convection to be one of several effects of decreased soil moisture favoring reduced precipitation over Europe in summer. Collini et al. (2008) speculated that the effects of decreased soil moisture on CIN were more important than its effects on CAPE for reducing precipitation during summer over southern Amazonia and the Brazilian highlands. Other modeling studies have not looked at CIN explicitly, but have instead focused on aspects such as mixed-layer equivalent potential temperature (e.g., Pal and Eltahir 2001). There have been few observational studies, as noted by Guo et al. (2006) and Zhang et al. (2008). Of these, it seems that only a single case study analysis has considered the interaction between soil moisture and CIN. Taylor et al. (2003) found that the effects of soil moisture on CIN on 28 August 2000 were the key factor controlling the presence or absence of moist convection during the following 2 days along a transect of the West African Sahel.

To summarize, high correlations among SM and most surface variables in Table 6 emphasize the strong landatmosphere interaction in Texas in summertime. As previously shown, precipitation affects soil moisture, and the latter plays an important role in controlling the surface variables and CIN by acting like a reservoir of water. By modulating the surface variables (especially $\mathrm{Td}$ ) and CIN, it is likely that soil moisture in turn feeds back on precipitation through an increase of $\mathrm{Td}$ and a decrease of CIN. These interactions result in strong links of precipitation with CIN as well as with soil moisture.

\section{Summary and conclusions}

Texas experiences warm season drought often, but predictability on monthly to seasonal time scales is very low. This study examined the modulation by convective instability of summertime precipitation in Texas and the important processes controlling convective instability. These processes were found to be typical features of droughts in the central United States, and they act by changing the thermodynamic structure and convective instability of the atmosphere. In particular, this study revealed how land-atmosphere feedbacks directly affect convective instability and its associated precipitation on a monthly time scale. The role of tropospheric processes will be explored in Part II.

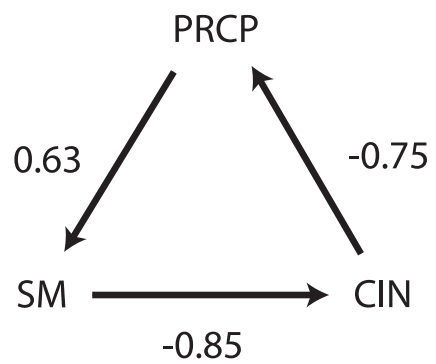

FIG. 5. Schematic diagram representing correlation coefficients between PRCP, SM, and CIN.

It was found that monthly mean precipitation is modified mainly by CIN rather than by CAPE or by precipitable water. This is because, despite large CAPE and moisture availability, convection is inhibited when CIN is large since $\mathrm{CIN}$ is a measure of the amount of energy needed to initiate convection. While dry (wet) months are caused by both fewer (more) rain days and lower (higher) intensity, CIN rather than CAPE or PW predominantly controls both the number of rain days and the intensity. Stronger correlation of CIN with the number of rain days $(-0.79)$ than with intensity $(-0.55)$ suggests that CIN modifies the number of rain days and the number of rain days affects the monthly precipitation.

Linear regression analysis revealed that warming at $700 \mathrm{hPa}$ (high Tlt) and surface dryness (low Td) combine to result in large CIN, leading to a precipitation deficit on monthly time scales. This is a novel finding, because most previous drought studies have emphasized only low relative humidity (large dewpoint depression) at the surface as causing a reduction in rainfall. The surface temperature, Ts, is tightly correlated with CIN and precipitation and is affected by both the free-atmospheric temperature at $700 \mathrm{hPa}$ (Tlt) through entrainment and by the surface sensible heat flux. Therefore, the variability of CIN is explained mostly by Td and the rest is explained by Tlt, rather than by Ts. The statistical independence of Tlt from Td suggests that different processes contribute to warming at $700 \mathrm{hPa}$ and to surface dryness, resulting in large CIN values in dry months.

The strong correlations among the precipitation, surface variables, and soil moisture imply that the thermodynamic surface variables such as $\mathrm{Td}$ are closely connected with precipitation processes. Note that the relation of the surface variables with PRCP resembles that with SM, with smaller correlation coefficients. This feature suggests that precipitation influences the surface variables through changing soil moisture. However, this study also suggests that the tight linkage between precipitation and soil moisture is not only due to the impacts of precipitation on soil moisture but is also due to the feedbacks of soil moisture on precipitation. 
This study emphasizes the important role of soil moisture in determining the precipitation deficit. One may expect that wetter soil tends to increase the moist static energy in the PBL and then increase the CAPE and rainfall (Pal and Eltahir 2001). However, it was found in this study that soil moisture affects rainfall through modulating the surface dewpoint and CIN rather than CAPE or PW. Although this study focused on the convective precipitation processes in Texas, the impacts of soil moisture prevail not only in the south-central United States (Koster et al. 2004) but also in the northern Great Plains and Midwest and in other locations around the world (Atlas et al. 1993; Lyon and Dole 1995; Trenberth and Cuillemot 1996; Pal and Eltahir 2001; Sud et al. 2003; Guo et al. 2006; Zhang et al. 2008). Pal and Eltahir (2001) reported that an asymmetry exists in the soil moisture-precipitation feedback in the midwestern United States, which is stronger in the case of drier soil moisture rather than that of wetter soil moisture. The strong feedbacks between precipitation and soil may make these regions vulnerable to warm season droughts. Therefore, the assimilation of unbiased observations of soil moisture and precise representations of soil moisturerainfall feedbacks in models are necessary to enhance our prediction of the warm season precipitation deficit and drought in the south-central and midwestern United States.

Because soil moisture is a feedback mechanism, it does not initiate droughts. Other mechanisms capable of initiating drought in Texas will be considered in Part II.

Acknowledgments. This work was partially supported by the National Science Foundation through Grant ATM-0089906.

\section{REFERENCES}

Atlas, R., N. Wolfson, and J. Terry, 1993: The effect of SST and soil moisture anomalies on GLA model simulations of the 1988 U.S. summer drought. J. Climate, 6, 2034-2048.

Beljaars, A. C. M., P. Viterbo, M. J. Miller, and A. K. Betts, 1996: The anomalous rainfall over the United States during July 1993: Sensitivity to land surface parameterization and soil moisture anomalies. Mon. Wea. Rev., 124, 362-383.

Betts, A. K., J. H. Ball, A. C. M. Beljaars, M. J. Miller, and P. Viterbo, 1996a: The land surface-atmosphere interaction: A review based on observational and global modeling perspectives. J. Geophys. Res., 101, 7209-7225.

_, S. Y. Hong, and H. L. Pan, 1996b: Comparison of NCEPNCAR reanalysis with 1987 FIFE data. Mon. Wea. Rev., 124, 1480-1498.

Biasutti, M., D. S. Battisti, and E. S. Sarachik, 2004: Mechanisms controlling the annual cycle of precipitation in the tropical Atlantic sector in an atmospheric GCM. J. Climate, 17, 47084723.

Bony, S., and Coauthors, 2006: How well do we understand and evaluate climate change feedback processes? J. Climate, 19, $3445-3482$.
Brotzge, J. A., 2004: A two-year comparison of the surface water and energy budgets between two OASIS Sites and NCEPNCAR reanalysis data. J. Hydrometeor., 5, 311-326.

Chen, P. Y., and P. M. Popovich, 2002: Correlation: Parametric and nonparametric measures. Sage University Papers Series on Quantitative Application in the Social Sciences 07-139, Sage Publications, $95 \mathrm{pp}$.

Clark, R. A., 1960: A study of convective precipitation as revealed by radar observation, Texas 1958-1959. J. Atmos. Sci., 4, 415-425.

Collini, E. A., E. H. Berbery, V. R. Barros, and M. E. Pyle, 2008: How does soil moisture influence the early stages of the South American monsoon? J. Climate, 21, 195-213.

DeMott, C. A., and D. A. Randall, 2004: Observed variations of tropical convective available potential energy. J. Geophys. Res., 109, D02102, doi:10.1029/2003JD003784.

Dirmeyer, P. A., Z. Guo, and X. Gao, 2004: Comparison, validation, and transferability of eight multiyear global soil wetness products. J. Hydrometeor., 5, 1011-1033.

_ represent the feedback between land and atmosphere? J. Hydrometeor., 7, 1177-1198.

Eltahir, E. A. B., 1998: A soil moisture-rainfall feedback mechanism. 1. Theory and observations. Water Resour. Res., 34, 765-776.

Findell, K., and E. A. B. Eltahir, 1999: Analysis of the pathways relating soil moisture and subsequent rainfall in Illinois. J. Geophys. Res., 104, 31 565-31 574.

Firestone, J. K., and B. A. Albrecht, 1986: The structure of the atmospheric boundary layer in the central equatorial Pacific during January and February of FGGE. Mon. Wea. Rev., 114, 2219-2231.

Fisher, R. A., 1921: On the "probable error" of a coefficient of correlation deduced from a small sample. Metron, 1, 3-32.

Fu, R., B. Zhu, and R. Dickinson, 1999: How do the atmosphere and land surface influence the seasonal changes of convection in tropical Amazon? J. Climate, 12, 1306-1321.

Grell, G. A., 1993: Prognostic evaluation of assumptions used by cumulus parameterizations. Mon. Wea. Rev., 121, 764-787.

Guo, Z., and Coauthors, 2006: GLACE: The Global LandAtmosphere Coupling Experiment. Part II: Analysis. J. Hydrometeor., 7, 611-625.

Helfand, H. M., and S. D. Schubert, 1995: Climatology of the Great Plains low-level jet and its contribution to the continental moisture budget of the United States. J. Climate, 8, 784-806.

Higgins, R. W., Y. Yao, E. S. Yarosh, J. E. Janowiak, and K. C. Mo, 1997: Influence of the Great Plains low-level jet on summertime precipitation and moisture transport over the central United States. J. Climate, 10, 481-507.

Hong, S.-Y., and H.-L. Pan, 2000: Impact of soil moisture anomalies on a seasonal, summertime circulation over North America in a regional climate model. J. Geophys. Res., 105, $29625-29634$.

—, and E. Kalnay, 2002: The 1998 Oklahoma-Texas drought: Mechanistic experiments with NCEP global and regional models. J. Climate, 15, 945-963.

Kalnay, E., and Coauthors, 1996: The NCEP/NCAR 40-Year Reanalysis Project. Bull. Amer. Meteor. Soc., 77, 437-471.

Kloesel, K. A., and B. A. Albrecht, 1989: Low-level inversions over the tropical Pacific-Thermodynamic structure of the boundary layer and above-inversion moisture structure. Mon. Wea. Rev., 117, 87-101.

Koster, R. D., and Coauthors, 2004: Regions of strong coupling between soil moisture and precipitation. Science, 305, 11381140. 
Lyon, B., and R. M. Dole, 1995: A diagnostic comparison of the 1980 and 1988 U.S. summer heat wave-drought. J. Climate, 8 , $1658-1675$.

Mapes, B. E., 2000: Convective inhibition, subgrid-scale triggering energy, and stratiform instability in a toy tropical wave model. J. Atmos. Sci., 57, 1515-1535.

Mintz, Y., 1984: The sensitivity of numerically simulated climates to land-surface boundary conditions. The Global Climate, J. T. Houghton, Ed., Cambridge University Press, 79-106.

Mo, K. C., J. E. Schlemm, H. Kim, and W. R. Higgins, 2006: Influence of initial conditions on summer precipitation simulations over the United States and Mexico. J. Climate, 19, 3640-3658.

Myoung, B., and J. W. Nielsen-Gammon, 2010a: Sensitivity of monthly convective precipitation to environmental conditions. J. Climate, 23, 166-188.

— and - 2010b: The convective instability pathway to warm season drought in Texas. Part II: Free-tropospheric modulation of convective inhibition. J. Climate, 23, 4474-4488.

Namias, J., 1982: Anatomy of Great Plains protracted heat waves (especially the 1980 U.S. summer drought). Mon. Wea. Rev., 110, 824-838.

NCDC, cited 2006: Billion dollar U.S. weather disasters 1980-2006. [Available online at http://www.ncdc.noaa.gov/oa/reports/ billionz.html.]

Oglesby, R. J., 1991: Springtime soil moisture, natural climatic variability, and North American drought as simulated by the NCAR Community Climate Model 1. J. Climate, 4, 890-897.

Pal, J. S., and E. A. B. Eltahir, 2001: Pathways relating soil moisture conditions to future summer rainfall within a model of the land-atmosphere system. J. Climate, 14, 1227-1242.

Roads, J., and A. Betts, 2000: NCEP-NCAR and ECMWF reanalysis surface water and energy budgets for the Mississippi River basin. J. Hydrometeor., 1, 88-94.

Rowntree, P. R., and J. A. Bolton, 1983: Simulation of the atmospheric response to soil moisture anomalies over Europe. Quart. J. Roy. Meteor. Soc., 109, 501-526.

Saha, S., and Coauthors, 2006: The NCEP Climate Forecast System. J. Climate, 19, 3483-3517.

Schär, C., D. Luthi, U. Beyerle, and E. Heise, 1999: The soilprecipitation feedback: A process study with a regional climate model. J. Climate, 12, 722-741.
Schubert, S. D., M. J. Suarez, P. J. Pegion, R. D. Koster, and J. T. Bacmeister, 2004: On the cause of the 1930s Dust Bowl. Science, 303, 1855-1859.

Steiger, J. H., 1980: Tests for computing elements of a correlation matrix. Psychol. Bull., 37, 245-251.

Stephens, G. L., and P. J. Webster, 1981: Clouds and climate: Sensitivity of simple systems. J. Atmos. Sci., 38, 235-247.

Sud, Y. C., and M. J. Fennessy, 1984: Influence of evaporation in semi-arid regions on the July circulation. J. Climatol., 4, 383-398.

, and W. E. Smith, 1985: Influence of local land-surface processes on the Indian monsoon: A numerical study. J. Climate Appl. Meteor., 24, 1015-1036.

— D. M. Mocko, K. M. Lau, and R. Atlas, 2003: Simulating the midwestern U.S. drought of 1988 with a GCM. J. Climate, 16, 3946-3965

Taylor, C. M., R. J. Ellis, D. J. Parker, R. R. Burton, and C. D. Thorncroft, 2003: Linking boundary-layer variability with convection: A case-study from JET2000. Quart. J. Roy. Meteor. Soc., 129, 2233-2253.

Trenberth, K. E., and G. W. Branstator, 1992: Issues in establishing causes of the 1988 drought over North America. J. Climate, 5, $159-172$

— , and C. J. Cuillemot, 1996: Physical process involved in the 1988 drought and 1993 floods in North America. J. Climate, 9, 1288-1298.

G. W. Branstator, and P. A. Arkin, 1988: Origins of the 1988 North American drought. Science, 242, 1640-1645.

Williams, E. J., 1959: The comparison of regression variables. J. Roy. Stat. Soc., 21B, 396-399.

Woodhouse, C. A., and J. T. Overpeck, 1998: 2000 years of drought variability in the central United States. Bull. Amer. Meteor. Soc., 79, 2693-2714.

Zhang, J., W.-C. Wang, and J. Wei, 2008: Assessing landatmosphere coupling using soil moisture from the Global Land Data Assimilation System and observational precipitation. J. Geophys. Res., 113, D17119, doi:10.1029/2008JD009807.

Zveryaev, I. I., and R. P. Allan, 2005: Water vapor variability in the tropics and its links to dynamics and precipitation. J. Geophys. Res., 110, D21112, doi:10.1029/2005JD006033. 